\title{
Corrigendum
}

\section{Corrigendum to "In Vitro Wound Healing Potential of Stem Extract of Alternanthera sessilis"}

\author{
Katyakyini Muniandy, ${ }^{1}$ Sivapragasam Gothai, ${ }^{1}$ Woan Sean Tan, ${ }^{1}$ S. Suresh Kumar, \\ Norhaizan Mohd Esa $\mathbb{D D}^{3}$ Govindasamy Chandramohan, ${ }^{4}$ Khalid S. Al-Numair, ${ }^{4}$ \\ and Palanisamy Arulselvan (iD) \\ ${ }^{1}$ Laboratory of Vaccines and Immunotherapeutics, Institute of Bioscience, Universiti Putra Malaysia, Serdang 43400, \\ Selangor, Malaysia \\ ${ }^{2}$ Department of Medical Microbiology and Parasitology, Faculty of Medicine and Health Sciences, Universiti Putra Malaysia, \\ Serdang 43400, Selangor, Malaysia \\ ${ }^{3}$ Department of Nutrition and Dietetics, Faculty of Medicine and Health Sciences, Universiti Putra Malaysia, Serdang 43400, \\ Selangor, Malaysia \\ ${ }^{4}$ Department of Community Health Sciences, College of Applied Medical Sciences, King Saud University, P.O. Box 10219, \\ Riyadh 11433, Saudi Arabia \\ ${ }^{5}$ Muthayammal Centre for Advanced Research, Muthayammal College of Arts and Science, Rasipuram, Namakkal, \\ Tamilnadu 637408, India
}

Correspondence should be addressed to Palanisamy Arulselvan; arulbio@gmail.com

Received 14 May 2020; Accepted 15 May 2020; Published 13 June 2020

Copyright (C) 2020 Katyakyini Muniandy et al. This is an open access article distributed under the Creative Commons Attribution License, which permits unrestricted use, distribution, and reproduction in any medium, provided the original work is properly cited.

In the article titled "In Vitro Wound Healing Potential of Stem Extract of Alternanthera sessilis" [1], an area of overlap was identified in the control $(0 \mathrm{~h})$ and allantoin $(0 \mathrm{~h})$ panels of Figure 4(a). The authors apologize for this error, which was due to the image being saved to the incorrect file location. With the agreement of the handling editor, the revised figure is shown below. 
$0 \mathrm{~h}$
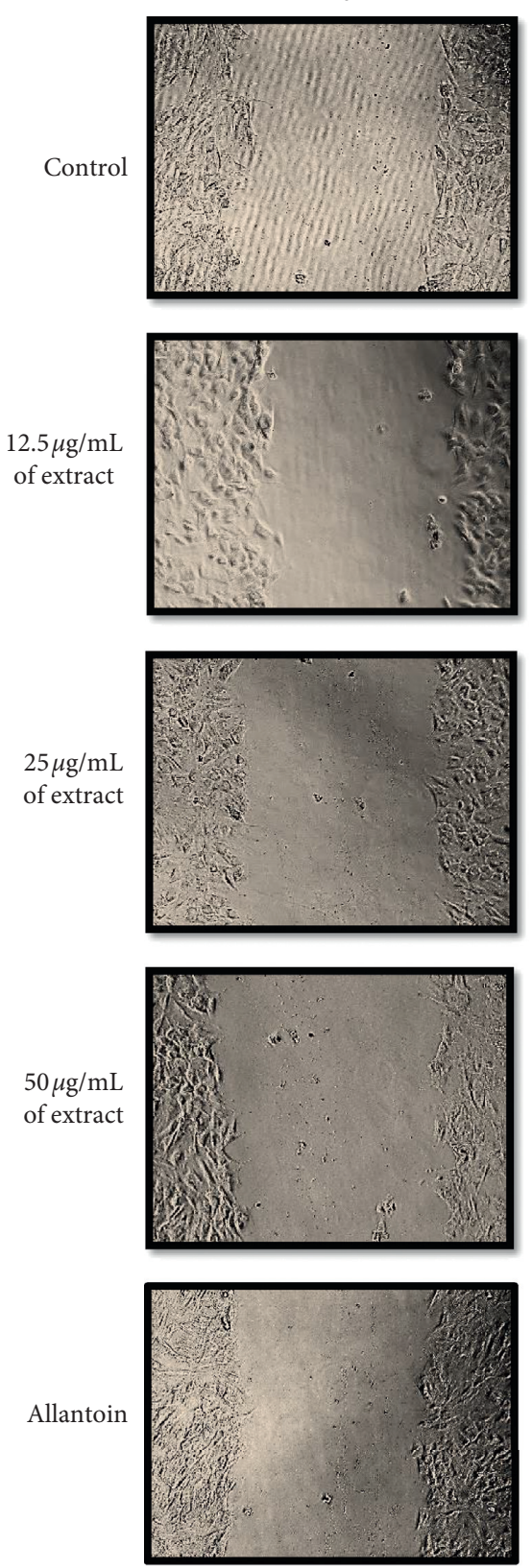

$24 \mathrm{~h}$
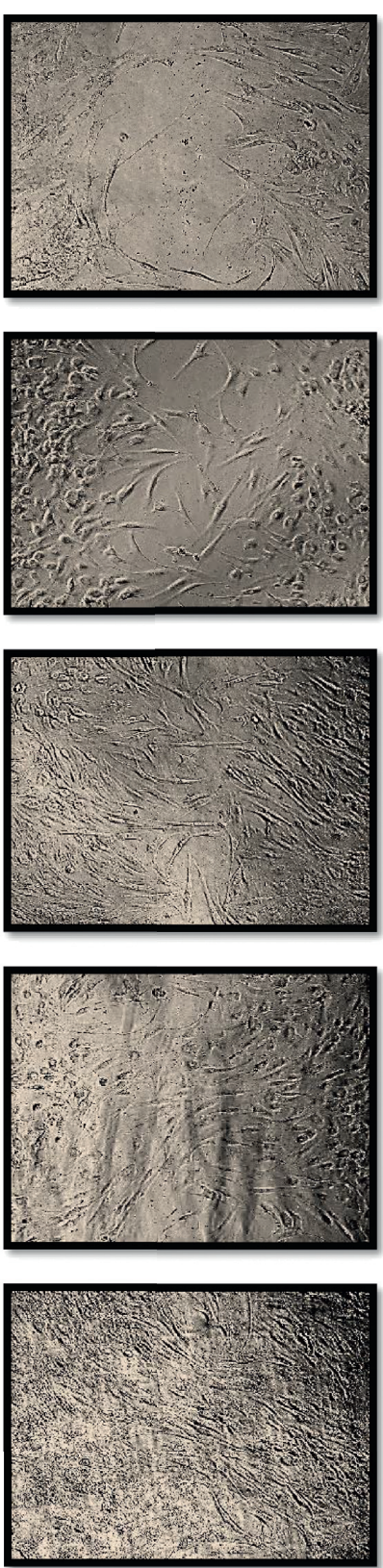

(a)

Figure 4: Continued. 
$\mathrm{oh}$
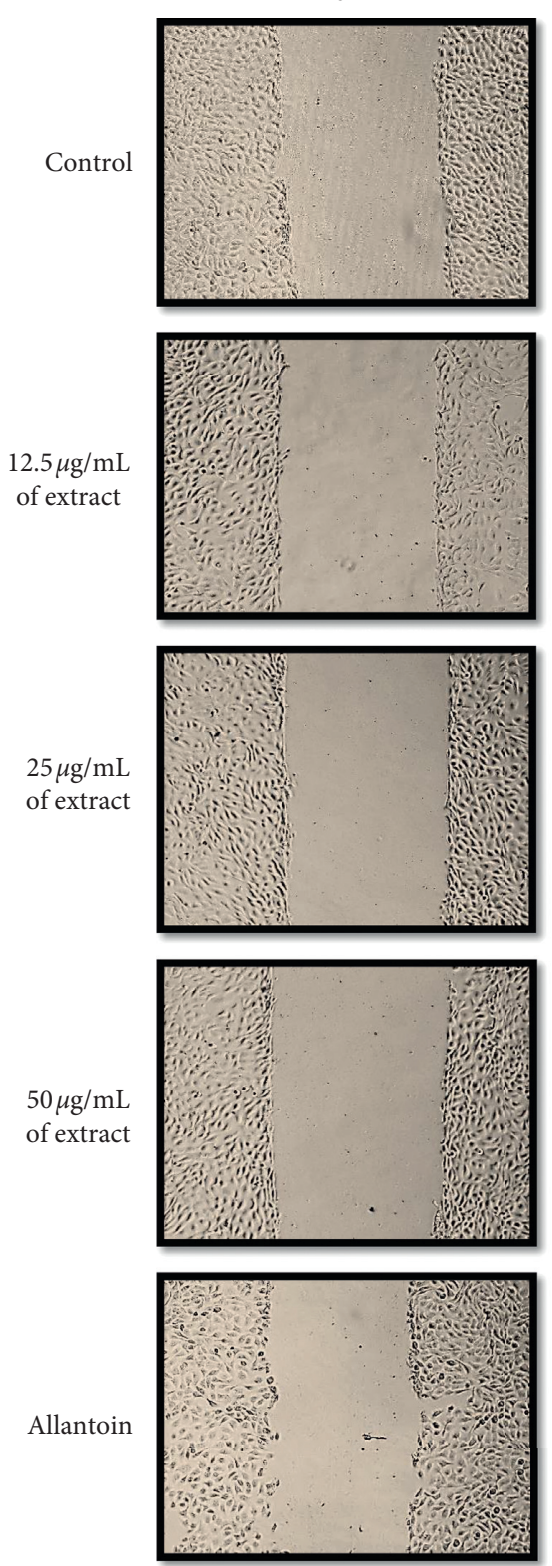

$24 \mathrm{~h}$
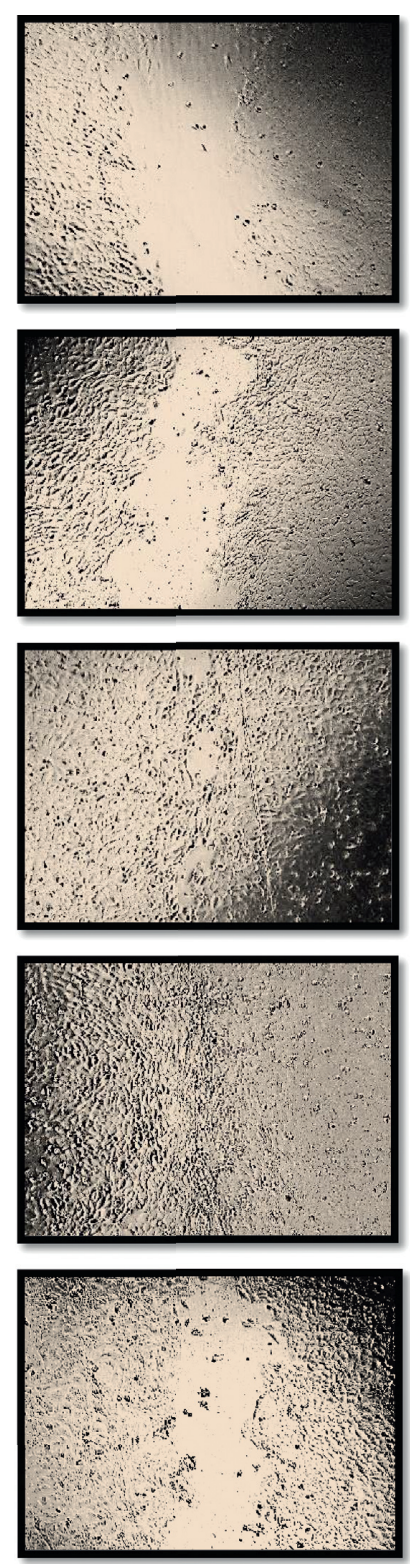

(b)

FIgUre 4: Continued. 

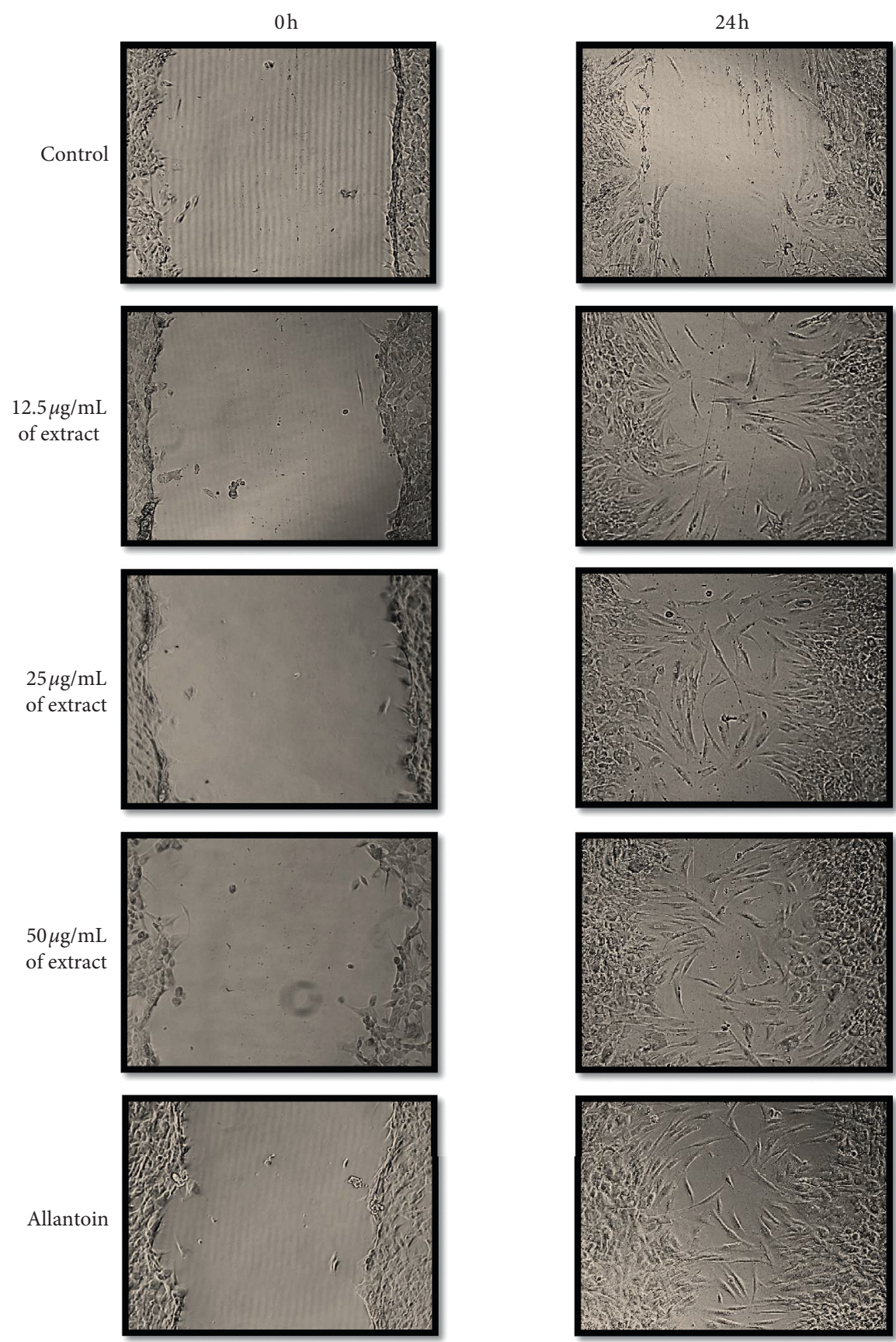

(c)

Figure 4: In vitro scratch assay ( $\times 40$ magnification). NHDF (a), HaCaT (b), and HDF-D (c) cells were scratched and treated with and without treatment of varying concentrations of plant extract. Ethanolic extract of stem part of A. sessilis showed positive cell proliferation and cell migration as compared with control group (without treatment).

\section{References}

[1] K. Muniandy, S. Gothai, W. S. Tan et al., "In vitro wound healing potential of stem extract of Alternanthera sessilis," Evidence-Based Complementary and Alternative Medicine, vol. 2018, Article ID 3142073, 13 pages, 2018. 